\title{
Correction to: Patterns of bone marrow aspiration confirmed hematological malignancies in Eritrean National Health Laboratory
}

Natnael Belai ${ }^{1 *}$, Amon Solomon Ghebrenegus ${ }^{2}$, Amin Ata Alamin ${ }^{3}$, Ghirmay Embaye ${ }^{4}$ and Amanuel Kidane Andegiorgish ${ }^{5}$

\section{Correction to: BMC Hematol}

https://doi.org/10.1186/s12878-019-0138-3

The original version of this article [1] unfortunately included an error to an author's name. Author Amin Ata Alamin was incorrectly presented as Anim Ata Alamin.

The correct author name has been included in the author list of this Correction article and is already updated in the original article.

\footnotetext{
Author details

'Orotta National Medical Surgical Referral Teaching Hospital, Asmara, Eritrea. ${ }^{2}$ Ghindae Zonal Referral Hospital, Ghindae, Eritrea. ${ }^{3}$ Department of Pathology, University of taif, Taif, Saudi Arabia. ${ }^{4}$ National Health Laboratory, Asmara, Eritrea. ${ }^{5}$ Asmara Collage of Health Science, Asmara, Eritrea.
}

Received: 24 May 2019 Accepted: 24 May 2019

Published online: 31 May 2019

\section{Reference}

1. Belai N, et al. Patterns of bone marrow aspiration confirmed hematological malignancies in Eritrean National Health Laboratory. BMC Hematol. 2019;19; 8. https://doi.org/10.1186/s12878-019-0138-3.

\footnotetext{
* Correspondence: desnat27@gmail.com

${ }^{1}$ Orotta National Medical Surgical Referral Teaching Hospital, Asmara, Eritrea

Full list of author information is available at the end of the article
} 